\title{
Processing Aluminum Nitride-Silicon Carbide Composites via Polymer Infiltration and Pyrolysis of Polymethylsilane, a Precursor to Stoichiometric Silicon Carbide
}

\author{
Kean W. Chew, ${ }^{*}, \dagger$ Alan Sellinger, ${ }^{\ddagger}$ and Richard M. Laine ${ }^{*}, \dagger$ \\ Departments of Materials Science and Engineering, Chemistry, and Macromolecular Science, and Engineering Center, \\ University of Michigan, Ann Arbor, Michigan, 48109
}

\begin{abstract}
AlN-SiC-particle-reinforced composites have been prepared at $\leq 1400^{\circ} \mathrm{C}$ using submicrometer AIN, -325 mesh $\alpha-\mathrm{SiC}$ particles, and polymethylsilane $\left(\mathrm{PMS} ;-\left(\mathrm{CH}_{3} \mathrm{SiH}\right)_{n}{ }^{-}\right)$ via a polymer infiltration and pyrolysis (PIP) process. PMS is an organometallic $\mathrm{SiC}$ polymer precursor that can be modified with $16 \mathrm{wt} \%$ cross-linking aid to provide mPMS. mPMS converts to nanocrystalline $\beta-\mathrm{SiC}$ with $>80 \%$ ceramic yield $\left(1000^{\circ} \mathrm{C}\right.$ in argon) with some excess $(<5 \mathrm{wt} \%)$ graphitic carbon. mPMS has been used successfully as a nonfugitive binder for AIN-SiC compacts. Densities of 2.5 versus $2.1 \mathrm{~g} / \mathrm{cm}^{3}$ have been obtained after nine PIP cycles for disk-shaped compacts formulated with and without mPMS binder, respectively. $\alpha$-SiC seeds crystallization of $\beta$-SiC derived from $\mathrm{mPMS}$ at temperatures as low as $1000^{\circ} \mathrm{C}$. Some evidence suggests that $\mathrm{AIN}-\mathrm{SiC}$ solid solutions form at particle/matrix interfaces.
\end{abstract}

\section{Introduction}

$\mathrm{P}$ ARTICULATE-REINFORCED ceramic-matrix composites (PRCs), when properly designed and processed, can offer superior high-temperature strength and stiffness, chemical inertness, and high specific strengths of potential use in advanced structural applications. ${ }^{1-6}$ Unfortunately, conventional processing of PRCs often results in microstructures with broad grainsize distributions that severely limit mechanical properties. ${ }^{6}$ Efforts to realize PRCs with better mechanical properties have recently focused on producing nanocomposite materials. There are now several reports on the processing and properties of fully dense $\mathrm{A} 1 \mathrm{~N}-\mathrm{SiC}$ and $\mathrm{Al}_{2} \mathrm{O}_{3}-\mathrm{SiC}$ nanocomposites. ${ }^{7-23} \mathrm{As}$ anticipated, these nanocomposite PRCs exhibit hightemperature fracture toughness, mechanical strength, and creep resistance superior to conventionally processed PRCs. These improvements are attributed to the refined microstructure ${ }^{13,15}$ and introduction of compressive stresses. ${ }^{10,11,23,24}$

There appears to be significant impetus for developing a wide variety of nanocomposite materials. Unfortunately, the literature on nanocomposite materials processing and property

C. G. Pantano-contributing editor

\footnotetext{
Manuscript No. 191057. Received April 28, 1997; approved August 26, 1997. Presented in part at the 20th Annual Cocoa Beach Conference on Composites, Advanced Ceramics, Materials, and Structures, Cocoa Beach, FL, Jan. 10, 1996.

Presented at the 98th Annual Meeting of the American Ceramic Society, Indianapolis, IN, Apr. 15, 1996 (Chemical Processing of Glasses and Ceramics Symposium, Paper No. SIX-3-96)

Supported by the U.S. Army Research Laboratory under Grant No. DOD-C-DAAL 04-91-C-0068.

Member, American Ceramic Society.

Department of Materials Science and Engineeering, Chemistry, and Macromolecular Science.

Engineering Center.
}

evaluation is quite limited, most likely because of inherent processing difficulties. Conventional processing methods are rarely amenable to processing nanocomposites, because the target grain sizes in the finished PRC mandate either ultrafine $(<100 \mathrm{~nm})$, crystalline starting powders or amorphous ${ }^{22}$ powders that subsequently crystallize. Even with appropriate materials, processing conditions must be chosen to avoid uncontrolled grain growth ${ }^{25}$ at temperatures necessary for consolidation. Other issues include difficulties in obtaining low-cost, high-purity, unagglomerated, nanosized ceramic powders, especially for non-oxides. ${ }^{25}$

Hot pressing (HPing) is the current method of choice for producing dense, nanocrystalline PRCs. ${ }^{8-16,20-24}$ For example, amorphous $\mathrm{Si}-\mathrm{C}-\mathrm{N}$ precursor powders can be HPed under nitrogen to form crystalline $\mathrm{Si}_{3} \mathrm{~N}_{4}$ matrices reinforced with nanosized $\mathrm{SiC}$ particles. ${ }^{22}$ Unfortunately, many processing constraints render HPing an impractical production method. ${ }^{26} \mathrm{~A}$ novel alternative to crystallization of amorphous powders relies on spinodal decomposition of solid solutions to provide nanocomposite PRCs, e.g., as found in the AlN-SiC system.

The structural similarity between $\mathrm{AlN}$ and $2 H-\alpha-\mathrm{SiC}$ favors interdiffusion and formation of solid solutions, rather than grain growth, when powders are HPed at $>2000^{\circ} \mathrm{C}^{8-10,12-16,20,21}$ Annealing the resulting solid solution $\left(\leq 1900^{\circ} \mathrm{C}\right)$ causes multidirectional spinodal decomposition ${ }^{27}$ to an $\mathrm{AlN}-\mathrm{SiC}$ nanocomposite with thermomechanical properties superior to the individual components. Kou and Virkar ${ }^{27}$ report modulated $\mathrm{AlN}-\mathrm{SiC}$ nanocomposite creep rates 3 times lower (values not provided) than AlN-SiC solid solutions with identical grain sizes. Huang and $\mathrm{Jih}^{13}$ find $\sim 20 \%$ increase in AlN-SiC nanocomposite hardnesses.

AlN-SiC PRCs can be obtained by pressureless sintering if additives $\left(\mathrm{Y}_{2} \mathrm{O}_{3}, \mathrm{Al}_{2} \mathrm{O}_{3} \text {, and } \mathrm{CaO}\right)^{7,17-19,28-30}$ are incorporated that allow liquid-phase sintering. These additives leave glassy phases at grain boundaries that provide improved toughness; however, their low viscosity can lead to unacceptable creep rates at high temperatures. ${ }^{28-30}$

Because of the above, considerable motivation remains to improve access to nanocomposite PRCs. Viable alternatives must offer short process times, simple processing methods, and access to structurally complex shapes. Low-cost, lowtemperature $\left(<1600^{\circ} \mathrm{C}\right)$, pressureless approaches that provide compositional and microstructural control are most preferable. Organometallic precursors offer one such alternative, because they transform at relatively low temperatures to nanocrystalline materials. ${ }^{31-35}$ For example, the low-cost SiC precursor, polymethylsilane (PMS; $\left.-\left(\mathrm{CH}_{3} \mathrm{SiH}\right)_{n}-\right)$ transforms to phase-pure and nanocrystalline $\mathrm{SiC}$ at temperatures $\geq 1000^{\circ} \mathrm{C}$. ${ }^{36}$

Unfortunately, only one brief report describes a precursor route to $\mathrm{AlN}-\mathrm{SiC}$ materials, ${ }^{31}$ and (to our knowledge) no reports discuss processing $\mathrm{AlN}-\mathrm{SiC}$ composites via powder/ precursor mixtures, despite the obvious attractions of this approach. Thus, the primary objectives of the work reported here are to (1) process $\mathrm{AlN}-\mathrm{SiC}$ nanocomposites using polymer 
infiltration and pyrolysis (PIP) of submicrometer AlN powder compacts, ${ }^{37-41}$ (2) determine if submicrometer AlN (crystallographically similar to $\alpha$-SiC) seeds $\mathrm{SiC}$ (PMS) crystallization in heat-treated AlN-PMS mixtures, and (3) study the processability of AlN-SiC composites using PMS binder and $\alpha-\mathrm{SiC}$ seeds. Secondary objectives include optimizing density gains per PIP cycle and evaluating the potential for forming AlN-SiC solid solutions at $<1600^{\circ} \mathrm{C}$. For practical purposes, in the work reported below, a 10 PIP cycle limit is the upper boundary chosen to achieve the above goals.

In the PIP process, a precursor liquid or solution is infiltrated into a shaped, porous ceramic body by capillary action or vacuum impregnation. ${ }^{1,37-41}$ The filled ceramic body then is heat-treated to convert the incorporated polymer to a ceramic. Repeated cycles are required to produce sufficiently dense components. Acceptable densities depend on the actual application, with structural components typically requiring near theoretical densities. ${ }^{1,42}$

PIP processing combines conventional shaping methods with low-temperature processing. Shaping and densification with PIP are always independent. Moreover, when the precursor is used as a nonfugitive precursor binder, (1) binder removal is obviated, (2) higher final densities are achievable, and (3) better control of final microstructure is obtained. ${ }^{43}$ Thus, complex and near-net-shape parts can be fabricated in a costeffective manner. In principle, most of the above criteria can be met with this approach. However, obtaining fully dense PRCs via PIP processing is nontrivial. The green densities of powder compacts (or fiber preforms for fiber-reinforced composites (FRCs)) are typically quite low, requiring multiple PIP cycles to achieve full density. ${ }^{39,41}$

Fortunately, a wide variety of low-cost organometallic and metalloorganic precursors for PIP processing are now available. The literature describes precursors to $\mathrm{SiC}, \mathrm{Si}_{3} \mathrm{~N}_{4}, \mathrm{AlN}$, $\mathrm{TiC}$, and aluminosilicates (celsian, mullite, and cordierite). ${ }^{35-38,41,44-48}$ To be useful for PIP processing, precursors must offer (1) ease of handling, (2) thermal and environmental stability, (3) well-defined molecular weight (MW) distribution and controllable rheology, (4) matrix and reinforcement wettability, and (5) a well-defined composition upon pyrolysis. ${ }^{33,38,40}$ These attributes are typically controlled by the polymer chemistry, architecture, and processing conditions, as discussed in detail elsewhere. ${ }^{33}$

Theoretically, the best precursor for $\mathrm{SiC}$ is PMS, with a number average molecular weight $\left(M_{\mathrm{n}}\right)$ of 2100 , with some excess carbon to obtain phase-pure $\mathrm{SiC}$, because unmodified PMS typically offers only moderate ceramic yields and generates $\mathrm{SiC}$ containing excess silicon. ${ }^{36}$

\section{Experimental Procedure}

\section{(1) General}

(A) Materials: AlN powder (99\% pure) was obtained from Tokuyama America, Inc. (San Mateo, CA), and $\alpha$-SiC and $\beta$-SiC powders (both $99 \%$ pure) were obtained from CERAC, Inc. (Milwaukee, WI) and H. C. Starck, Inc. (Newton, MA), respectively. (See Fig. 1.) The reported average particle size of the Grade-F AlN powder (lot 48040) and $\alpha-S i C$ powder (lot X13385) were 0.3 and $10-20 \mu \mathrm{m}$, respectively. The asreceived powders were heated $\left(10^{\circ} \mathrm{C} / \mathrm{min}\right.$ under argon) to $1000^{\circ} \mathrm{C}$ in $1 \mathrm{~h}$ to remove adventitious water or organics.

(B) Pyrolysis Conditions: All pyrolyses $\leq 1200^{\circ} \mathrm{C}$ were conducted in a sealed and ported quartz tube $(5.7 \mathrm{~cm}$ throat ID $\times 71.1 \mathrm{~cm}$ length) under argon $(100 \mathrm{~mL} / \mathrm{min})$ using a tube furnace (Furnace Model HTF 55322A and Controller Model CC58114PC, Lindberg/Blue M, Watertown, WI). Pyrolyses to $1400^{\circ} \mathrm{C}$ were run under argon $(100 \mathrm{~mL} / \mathrm{min})$ in a hightemperature tube furnace (Model F54348CM, Barnstead/ Thermolyne, Dubuque, IA) in a sealed and ported mullite tube equipped with a water-cooled aluminum end cap.

(C) Composite Processing: Two types of composites, with and without mPMS binder, were produced. No other additves were used to avoid contamination. The synthesis of mPMS has been described elsewhere. ${ }^{48}$ mPMS or mPMS-4, unless otherwise specified, refers to a precursor with $\mathrm{C}_{1.41} \mathrm{Si}_{1.00} \mathrm{~B}_{0.020}$ stoichiometry. Three other derivatives were also studied (see Table I), but mPMS-4 was optimal for PIP processing.

\section{(2) Sample Fabrication and Heat Treatment}

Three types of composite disks were made: (1) pure AlN with mPMS-4 binder, (2) AlN- $\alpha-S i C$ without mPMS-4 binder, and (3) AlN- $\alpha-S i C$ with mPMS-4 binder. Disks fabricated with pure AlN had insufficient green strength and exhibited shear failure; pure AlN with mPMS-4 binder compacts pressed easily but were weak after heat treatment, and surface cracks were visible. AlN- $\alpha$-SiC composite disks fabricated using a 9:1 (by weight) ratio powder mixture provided good green strength and ease of handling. This powder ratio was established empirically but not optimized. $\alpha-\mathrm{SiC}$ was used as a reinforcement (1) because the $\mathrm{AlN}-\alpha-\mathrm{SiC}$ mixtures with mPMS-4 demonstrated the best handling characteristics and (2) to minimize confusion with polymer-derived $\beta$-SiC.

(A) Pure AlN and AlN- $\alpha-S i C$ Compacts with mPMS Binder: All operations were conducted in an argon glove box (Model MO-40-2 Dri-Lab glove box, Vacuum Atmospheres, Hawthorne, CA). Dilute mPMS-4 ( 12 wt\% polymer in toluene/tetrahydrofuran (THF)) was added to pure AlN to obtain a 3:1 and 1:3 composition of AlN and mPMS-4 after vacuum removal of solvent. A 9:1 (by weight) $\mathrm{AlN}-\alpha-\mathrm{SiC}$ powder mixture was mixed thoroughly. Then, dilute mPMS-4 was added to this mixture to obtain, after vacuum removal of solvent, $(\mathrm{AlN}-\alpha-\mathrm{SiC})_{1-x}(\mathrm{mPMS}-4)_{x}$ compositions where $x=10$, 20,25 , or $30 \mathrm{wt} \%$.

The dried powder/binder mixture (typically $\sim 0.4 \mathrm{~g}$ ) then was poured into a double-action stainless-steel die $(12.72 \mathrm{~mm} \mathrm{ID} \times$

Table I. Nomenclature and Composition of Different mMPS Precursors

\begin{tabular}{|c|c|c|}
\hline $\begin{array}{l}\text { Precursor } \\
\text { name }\end{array}$ & $\begin{array}{l}\text { Precursor } \\
\text { stoichiometry }\end{array}$ & Ceramic products \\
\hline mPMS-1 & $\mathrm{C}_{1.20} \mathrm{Si}_{1.00} \mathrm{~B}_{0.010}$ & $\beta-\mathrm{SiC}$ and silicon \\
\hline mPMS-2 & $\mathrm{C}_{125} \mathrm{Si}_{100} \mathrm{~B}_{0012}$ & Stoichiometric $\beta-\mathrm{SiC}$ \\
\hline mPMS-3 & $\mathrm{C}_{1.30} \mathrm{Si}_{1.00} \mathrm{~B}_{0.014}$ & $\begin{array}{l}\beta-\mathrm{SiC} \text { and } \sim 1 \text { wt } \% \text { graphitic } \\
\text { carbon }\end{array}$ \\
\hline mPMS-4 & $\mathrm{C}_{1.41} \mathrm{Si}_{1.00} \mathrm{~B}_{0.020}$ & $\begin{array}{l}\beta-\mathrm{SiC} \text { and } \leq 5 \text { wt } \% \text { graphitic } \\
\text { carbon }\end{array}$ \\
\hline
\end{tabular}

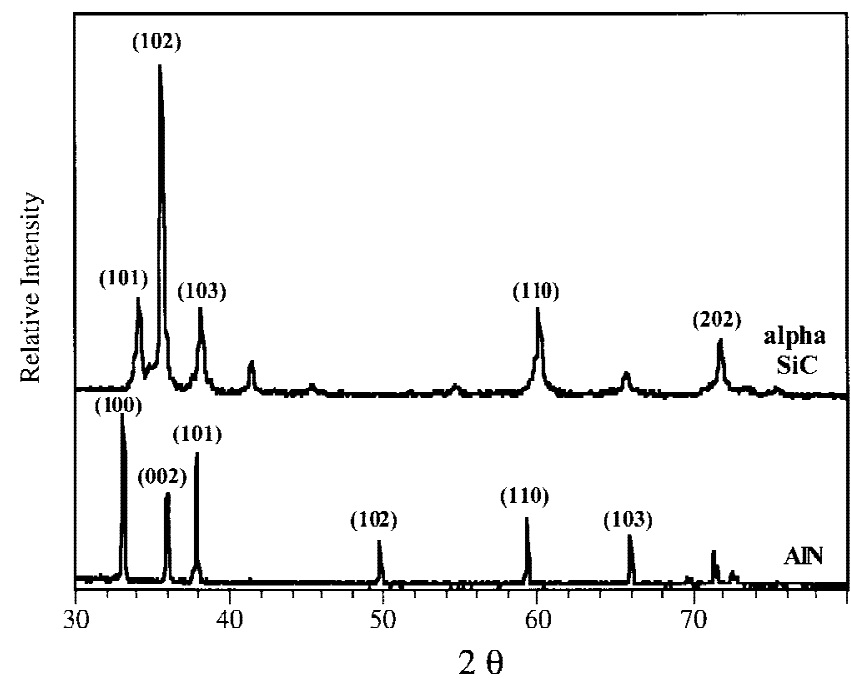

Fig. 1. XRDs of as-received $\alpha-\mathrm{SiC}$ and AlN powders. 
$50.8 \mathrm{~mm}$ height). The assembled die was removed from the glove box and uniaxially compressed to $138 \mathrm{MPa}$ (20 ksi) (Model C laboratory press, Carver, Wabash, IN). The compressive load was removed after the pressure had stabilized for $\geq 5$ min and the disk ejected from the die under a protective inert atmosphere (typically nitrogen gas).

The disks $(12.72 \mathrm{~mm} \times \sim 1.9 \mathrm{~mm})$ were transferred rapidly onto graphite-foil-lined alumina holders inside a sealed and ported quartz furnace tube. The quartz tube was purged with argon $(10 \mathrm{~min})$ and then heated $\left(10^{\circ} \mathrm{C} / \mathrm{min}\right.$ under argon) to $1000^{\circ} \mathrm{C}$ to convert the mPMS to $\beta-\mathrm{SiC}(\mathrm{SiC}$ (mPMS)). After heat treatment, the quartz tube was returned to the glove box, following three degassing steps in the antechamber. The disk dimensions and weight were noted with digital calipers (Model CD-6" C, Mitutoyo Corp., Tokyo, Japan) and a precision balance (Model PJ360 DeltaRange ${ }^{\circledR}$, Mettler, Highstown, NJ).

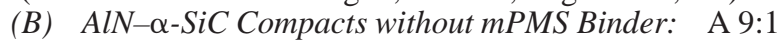
(by weight) ratio powder mixture was mixed thoroughly in air ( $15 \mathrm{~min})$ and then ultrasonicated for $10 \mathrm{~min}$ (Model 1200, Bransonic Ultrasonic Cleaner, Danbury, CT). The powder mixture (typically $\sim 0.4 \mathrm{~g}$ ) then was carefully poured into a doubleaction 316-stainless-steel die in air and compressed uniaxially, as above. The compressive load was removed after the pressure stabilized for $\geq 5$ min and the disk ejected.

Disks $(12.7 \mathrm{~mm} \times 1.9 \mathrm{~mm})$ were degassed under vacuum $(<1$ torr $(\sim 133 \mathrm{~Pa}))$ in the antechamber of an argon glove box. They then were transferred into the glove box, placed on graphitefoil-lined alumina boats $(6.0 \mathrm{~cm} \times 3.0 \mathrm{~cm} \times 1.4 \mathrm{~cm})$, sealed in a ported quartz tube, and then transferred out for heat treatment. Disks without binder were heated in the quartz tube $\left(10^{\circ} \mathrm{C} / \mathrm{min}\right.$ under argon to $\left.1000^{\circ} \mathrm{C}\right)$ to eliminate adsorbed water, surface coatings, or organics introduced during sample preparation. The quartz tube was resealed and returned to the glove box after heat treatment. The disk dimensions were recorded as above.

\section{(3) Polymer Infiltration and Pyrolysis Process}

Disks (with and without $\alpha$-SiC) were immersed for $12 \mathrm{~h}$ in dilute (12 wt \% solids loading in toluene/THF) mPMS in tightly capped vials. The disks were removed from the vials, dried, placed into the quartz pyrolysis tube and transferred to a furnace. The heating schedules (Tables II and III) were designed according to the PMS thermogravimetric analysis (TGA) weight-loss behavior (Fig. 2). Disk weights and dimensions were recorded after each cycle and then polished (see below). The disks then were reimpregnated with mPMS solution as above and repyrolyzed.

Two different heating schedules were used. The initial $12 \mathrm{~h}$ program (Table II) was used to avoid damaging the relatively weak green compacts. The ramp rates for the second pyrolysis program were double those of the first.

Two procedures were used to ensure maximum polymer infiltration per cycle. The first involved gently polishing the disk (900 grit SiC paper, Mager Scientific, Dexter, MI) after each cycle to remove the thin $\mathrm{SiC}$ (mPMS) coatings that formed and inhibited subsequent infiltration. The second used intermediate $1200^{\circ}$ or $1400^{\circ} \mathrm{C}$ heat treatments to densify the $\mathrm{SiC}(\mathrm{mPMS})$ and reopen $\mathrm{SiC}(\mathrm{mPMS})$-filled pores. The occur-

Table II. Slow Ramp Rate Heating Program with mPMS-4 Binder

\begin{tabular}{ccc}
\hline $\begin{array}{c}\text { Temperature } \\
\text { range }\left({ }^{\circ} \mathrm{C}\right)\end{array}$ & $\begin{array}{c}\text { Ramp rate } \\
\left({ }^{\circ} \mathrm{C} / \mathrm{h}\right)\end{array}$ & $\begin{array}{c}\text { Dwell time } \\
(\mathrm{h})\end{array}$ \\
\hline $20-100$ & 60 & 0.5 \\
$100-200$ & 120 & 0.5 \\
$200-250$ & 60 & 0 \\
$250-350$ & 120 & 0.5 \\
$350-470$ & 60 & 0.5 \\
$470-550$ & 120 & 0.5 \\
$550-1000$ & 300 & 1.0 \\
$1000-20$ & 300 & End \\
\hline
\end{tabular}

\begin{tabular}{ccc}
$\begin{array}{c}\text { Table III. } \\
\text { Program for Composites during } \\
\text { mPMS Processing }\end{array}$ \\
\hline $\begin{array}{c}\text { Temperature } \\
\text { range }\left({ }^{\circ} \mathrm{C}\right)\end{array}$ & $\begin{array}{c}\text { Ramp rate } \\
\left({ }^{\circ} \mathrm{C} / \mathrm{h}\right)\end{array}$ & $\begin{array}{c}\text { Dwell time } \\
(\mathrm{h})\end{array}$ \\
\hline $20-100$ & 120 & 0.5 \\
$100-200$ & 240 & 0.5 \\
$200-250$ & 240 & 0 \\
$250-350$ & 240 & 0.5 \\
$350-470$ & 300 & 0.5 \\
$470-550$ & 300 & 0.5 \\
$550-1000$ & 600 & 1.0 \\
$000-20$ & 600 & End \\
\hline
\end{tabular}

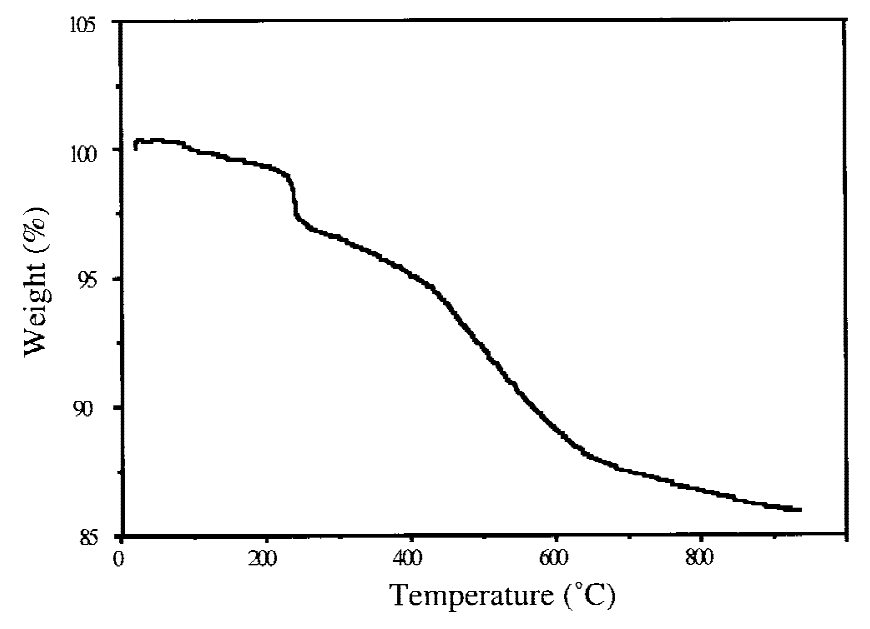

Fig. 2. Decomposition profile of vacuum-dried mPMS-4 in argon.

rence of the latter process was inferred from the improved infiltration behavior that results.

\section{(4) Characterization}

TGA studies were performed (Model Hi-Res TGA 2950 thermogravimetric analyzer, TA Instruments, Inc., New Castle, DE). Samples (15-30 mg) were placed in a platinum pan and heated under argon $(60 \mathrm{~mL} / \mathrm{min})$ at $50^{\circ} \mathrm{C} / \mathrm{min}$ (HiRes mode 4) from room temperature to $1000^{\circ} \mathrm{C}$. Sample stabilities in air were assessed by placing 15-30 mg samples in the TGA furnace. A $30 \mathrm{~s}$ flow $(60 \mathrm{~mL} / \mathrm{min})$ of prepurified, dry air $\left(\mathrm{CO}_{2}\right.$ free) was introduced into the sample chamber after purging with argon $(60 \mathrm{~mL} / \mathrm{min})$ for $5 \mathrm{~min}$. The sample weight gain with time was recorded over a period of $5 \mathrm{~h}$.

Differential thermal analyses (DTA) studies were performed (Model DSC 2910 module equipped with a $1600^{\circ} \mathrm{C}$ differential thermal analyzer cell, TA Instruments, Inc.). Samples (10-15 $\mathrm{mg}$ ) were placed inside platinum sample cups lined with platinum foil and heated at $10^{\circ} \mathrm{C} / \mathrm{min}$ under argon $(50 \mathrm{~mL} / \mathrm{min})$ to $1400^{\circ} \mathrm{C} . \alpha-\mathrm{Al}_{2} \mathrm{O}_{3}$ was used as the reference material.

Diffuse reflectance infrared Fourier transform spectroscopy (DRIFTS) spectra of disk specimen surfaces were obtained (Model Galaxy Series FTIR 3020 spectrometer, Mattson Instruments, Inc., Madison, WI) equipped with a "praying mantis" DRIFTS accessory (Model DCA-02, Harrick Scientific Corp., Ossining, NY) and dry-nitrogen-gas purge assembly. Random cuttings of optical-grade $\mathrm{KBr}$ (International Crystal Laboratories, Garfield, NJ) were ground using a dry alumina mortar and pestle. The ground $\mathrm{KBr}$ powder $(\sim 0.150 \mathrm{~g})$ was compacted uniaxially into a hardened 316-stainless-steel cylindrical die at $138 \mathrm{MPa}(20 \mathrm{ksi})$ for $15 \mathrm{~min}$. The resulting $\mathrm{KBr}$ pellet $(<0.5 \mathrm{~mm}$ thick) then was placed above the specimen disk in a sample holder and transferred into the sample chamber. 250 scans were collected for each specimen at a gain of 20 and resolution of $\pm 2 \mathrm{~cm}^{-1}$. 
Spectra of as-received powders and AlN-mPMS powder mixtures were obtained by grinding a $1.0 \mathrm{wt} \%$ sample with cuttings of optical-grade $\mathrm{KBr}$ in a dry alumina mortar and pestle in the glove box. The ground mixture then was packed into a sample cup and transferred into the specimen chamber. 500 scans were collected for each sample at a gain of 4 and resolution of $\pm 4 \mathrm{~cm}^{-1}$.

$\mathrm{X}$-ray diffractometry (XRD) was used to follow development as samples were pyrolyzed to $1000^{\circ}-1400^{\circ} \mathrm{C}$ (under argon for $1 \mathrm{~h}$ ). Spectra were collected using a rotating anode goniometer (Rigaku Denki Co., Ltd., Tokyo, Japan). Standard operating conditions are described elsewhere. ${ }^{36,45}$

Field-emission-gun scanning electron microscopy (SEM; Model S-800, Hitachi, Ltd., Tokyo, Japan) was used for microstructural characterization. Samples were cut from disks using a high-speed precision saw (Model Isomet 2000, Buehler, Ltd., Lake Bluff, IL) equipped with a diamond wafering blade. Specimen surfaces were polished with 900 grit $\mathrm{SiC}$ paper and ultrasonically cleaned. An operating voltage of $5.0 \mathrm{kV}$ was used.

\section{Results and Discussion}

We describe here efforts to develop processing-microstructural relationships for PIP-processed AlN-SiC composites made with $\mathrm{mPMS}$ as binder and infiltrant. In particular, we are interested in the influence of variations in processing conditions and additives on composite densification and microstructural development.

Three different PIP-processed AlN-SiC systems were studied: (1) pure AlN with mPMS binder, (2) AlN- $\alpha-S i C$ (9:1 (by weight)) without mPMS binder, and (3) AlN- $\alpha-\mathrm{SiC}$ (9:1 (by weight)) with mPMS-4 binder. The first system shows conclusively that AlN does not seed SiC (mPMS) crystallization and produces low-toughness compacts that are difficult to handle. The second system (10 wt $\% \alpha-S i C$ added) provides improved green compact strength but lower final compact densities. The third system offers the best green strength and final densities ( $2.5 \mathrm{~g} / \mathrm{cm}^{3}$ after nine PIP cycles). In the latter two systems, the added $\alpha$-SiC seeds crystallization, as reported by Bill and co-workers and by us. ${ }^{49,50}$

\section{(1) Polymethylsilane}

PMS can be synthesized using a variety of approaches. ${ }^{33,36,48}$ The mPMS used here derives from sodium dehalocoupling of methyldichlorosilane $\left(\mathrm{CH}_{3} \mathrm{SiHCl}_{2}\right)$ per Sellinger ${ }^{48}$ and represents an optimized precursor in terms of ceramic yield, phase purity, stoichiometry, and air stability. mPMS is a hyperbranched polymer with $M_{\mathrm{n}} \approx 2100$ and polydispersity index (PDI) of $\sim 7.1$ but with a significant fraction of the polymer consisting of MW $>10 \times 10^{3}$ dalton $(\mathrm{amu})$, which provides processability. ${ }^{48}$ The composition of this mPMS is approximately $\mathrm{C}_{1.41} \mathrm{Si}_{1.00} \mathrm{~B}_{0.02}$.

\section{(2) Precursor Properties/Pyrolysis Behavior}

(A) TGA: The theoretical SiC ceramic yield for PMS is 91\% (Eq. (1)). TGA studies of vacuum-dried mPMS show a ceramic yield $(\mathrm{CY})$ of $\sim 85 \%\left(1000^{\circ} \mathrm{C}\right.$, Fig. 2$)$. The lower $\mathrm{CY}$ observed (versus theory) results from volatilization of low-MW cyclic mPMS oligomers $\left(2.5 \mathrm{wt} \%\right.$ at $\left.250^{\circ} \mathrm{C}\right) .{ }^{48}$ The major mass loss region occurs over a $600^{\circ} \mathrm{C}$ temperature range, from $250^{\circ}$ to $800^{\circ} \mathrm{C}$. An additional 3-4 wt $\%$ mass loss occurs from $800^{\circ}$ to $1450^{\circ} \mathrm{C}$. This latter loss is atributed to elimination of residual hydrogen gas from $\mathrm{Si}-\mathrm{H}$ groups (observed by DRIFTS), leading to a final $\mathrm{CY}$ of $\sim 80 \mathrm{wt} \%$ at $1400^{\circ} \mathrm{C}$. Air stability tests show that solvent-free mPMS oxidizes slowly. Samples gain only $3 \mathrm{wt} \%$ after $5 \mathrm{~h}$ in static dry air. Consequently, brief polymer exposure to air becomes feasible.

$$
\left[\begin{array}{c}
\mathrm{CH}_{3} \\
\mathrm{I} \\
\mathrm{Si} \\
\mathrm{I} \\
\mathrm{H}
\end{array}\right]_{n} \underset{\Delta, \mathrm{Ar}}{\longrightarrow} \beta-\mathrm{SiC}+2 \mathrm{H}_{2}
$$

(B) DTA: Figure 3 shows the DTA events that occur during the polymer-to-ceramic conversion of vacuum-dried mPMS. This DTA is substantially different from that reported previously by Zhang. ${ }^{36}$ The first broad exotherm, centered at $160^{\circ} \mathrm{C}$, appears to result from cross-linking reactions that render the polymer infusible. ${ }^{36}$ The second, sharp exotherm at $250^{\circ} \mathrm{C}$ is associated with a second curing mechanism likely resulting from thermally promoted hydrosilylation, as discussed below.

A small exotherm at $400^{\circ}-500^{\circ} \mathrm{C}$ can be assigned to the Kumada rearrangement. ${ }^{36}$ Hydrogen-gas evolution begins at $\sim 700^{\circ} \mathrm{C},{ }^{36}$ as indicated by a broad exotherm centered at $790^{\circ} \mathrm{C}$. A final exotherm for $\beta$-SiC crystallization occurs at $\sim 1030^{\circ} \mathrm{C}$ (maximum), as confirmed by XRD (see below).

(C) XRD: XRDs of mPMS-2 heated at $1000^{\circ}-1400^{\circ} \mathrm{C}$ show the appearance of $\beta$-SiC (Table IV and Fig. 4). Similar to the work of Zhang, very broad peaks appear in samples heated to $1000^{\circ} \mathrm{C}$, suggesting nanocrystalline material. Samples heated to $1200^{\circ}$ or $1400^{\circ} \mathrm{C}$ undergo some grain growth, as evidenced by peak sharpening. However, the peaks remain broad, even at $1400^{\circ} \mathrm{C}$, indicating that the material remains nanocrystalline. These observations are supported by TEM and nuclear magnetic resonance (NMR) studies to be published elsewhere. ${ }^{51}$ The average grain sizes (from TEM of SiC fibers from $\left.\mathrm{mPMS}^{36}\right)$ are $\sim 1 \mathrm{~nm}\left(1000^{\circ} \mathrm{C}\right), 10 \mathrm{~nm}\left(1200^{\circ} \mathrm{C}\right), 25 \mathrm{~nm}$ $\left(1400^{\circ} \mathrm{C}\right), 60 \mathrm{~nm}\left(1600^{\circ} \mathrm{C}\right)$, and $200-500 \mathrm{~nm}\left(1800^{\circ} \mathrm{C}\right) .{ }^{51}$

The amount of cross-linking agent present in PMS strongly affects CY, phase purity (Fig. 5), and stoichiometry. Unmodified PMS exhibits CYs of $\sim 55 \mathrm{wt} \%$ at $1000^{\circ} \mathrm{C}$ and forms $\beta$-SiC with excess silicon (up to $20 \mathrm{wt} \%$ ). ${ }^{48}$ In contrast, mPMS-2 (see Table I for composition) has a CY of $\sim 80 \mathrm{wt} \%$ at $1000^{\circ} \mathrm{C}$, with only $\beta$-SiC detected by XRD. mPMS-3 gives an 85 wt $\%$ CY with $\sim 1 \mathrm{wt} \%$ carbon. Finally, mPMS (mPMS-4) provides a $\mathrm{CY}$ of $\sim 85 \mathrm{wt} \%$ and forms $\beta-\mathrm{SiC}$ with $\leq 5 \mathrm{wt} \%$ graphitic carbon (see XRD section). The carbon contents are estimated from observed CYs and initial precursor compositions.

XRDs of mPMS- 1 show only $\beta-\mathrm{SiC}$ at $1200^{\circ} \mathrm{C}(1 \mathrm{~h})$, with excess silicon appearing only at $1400^{\circ} \mathrm{C}$. There are several possible explanations for this behavior. We know from TGA results that an $\sim 3 \%$ mass loss occurs at $1200^{\circ}-1400^{\circ} \mathrm{C}$. Below $1200^{\circ} \mathrm{C}$, considerable hydrogenated, amorphous $\mathrm{SiC}$ is present, which is undetectable by XRD. At $\geq 1200^{\circ} \mathrm{C}$, it appears that isolated hydrogen atoms begin to diffuse at reasonable rates, leading to formation and evolution of hydrogen gas and the generation of free silicon, which undergoes near-melt crystallization.

For the PIP studies, we selected a version of mPMS (mPMS4) that provides excess carbon on pyrolysis. It had been anticipated that this excess carbon would carbothermally reduce the oxide surface layers present on the particulate-reinforcing pow-

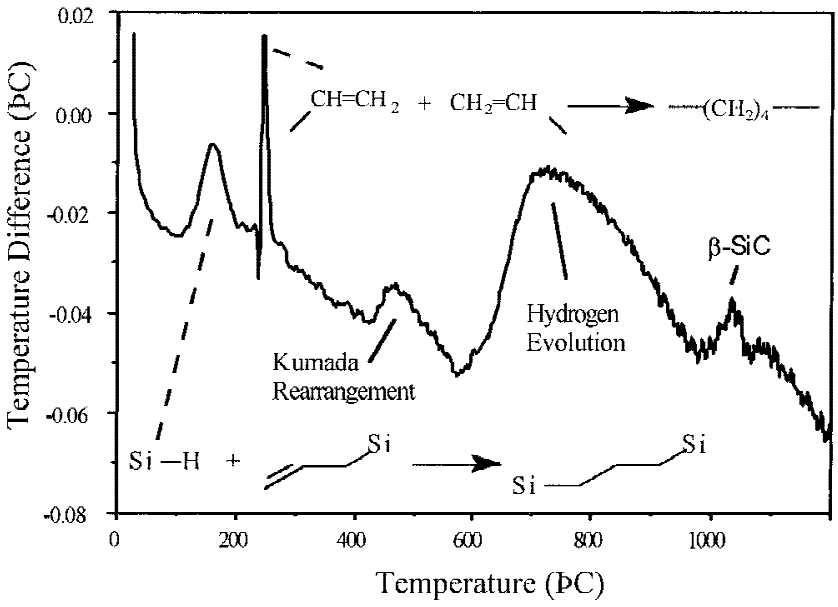

Fig. 3. DTA profile of vacuum-dried mPMS-4. 
Table IV. Primary XRD Peaks of Interest for $\alpha-$ and $\beta$-SiC

\begin{tabular}{llcc}
\hline \multicolumn{2}{c}{$\alpha$-SiC } & \multicolumn{2}{c}{$\beta$-SiC } \\
\cline { 3 - 4 }$h k l$ & $\operatorname{deg} 2 \theta$ & $h k l$ & $\operatorname{deg} 2 \theta$ \\
\hline 102 & 35.66 & 111 & 35.60 \\
104 & 41.40 & 200 & 41.38 \\
110 & 59.99 & 220 & 59.98 \\
202 & 71.78 & 311 & 71.78 \\
\hline
\end{tabular}

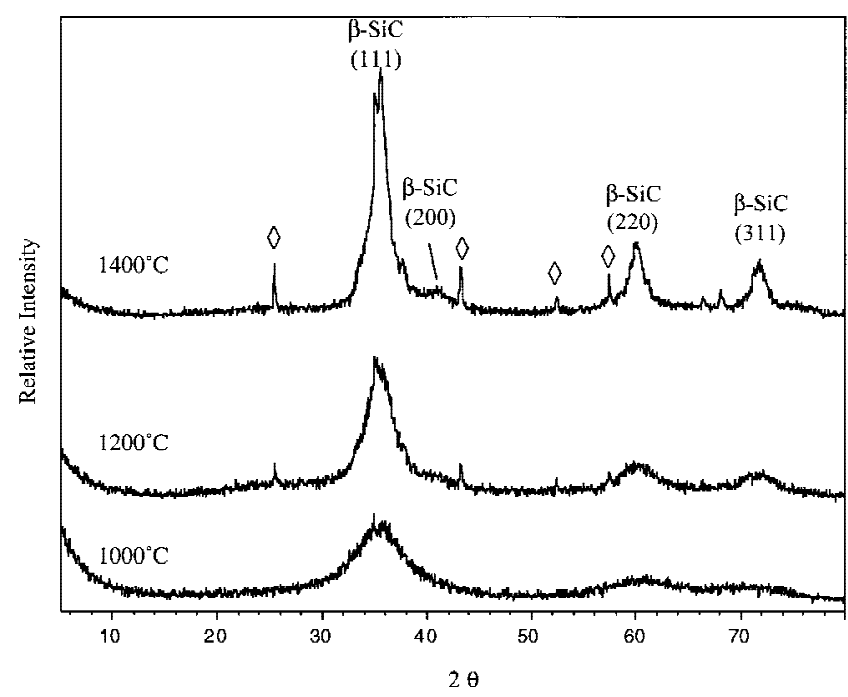

Fig. 4. Stacked XRDs of mPMS-4 after pyrolysis for $2 \mathrm{~h}$ in $\operatorname{argon}$ $((\diamond)$ graphitic carbon).

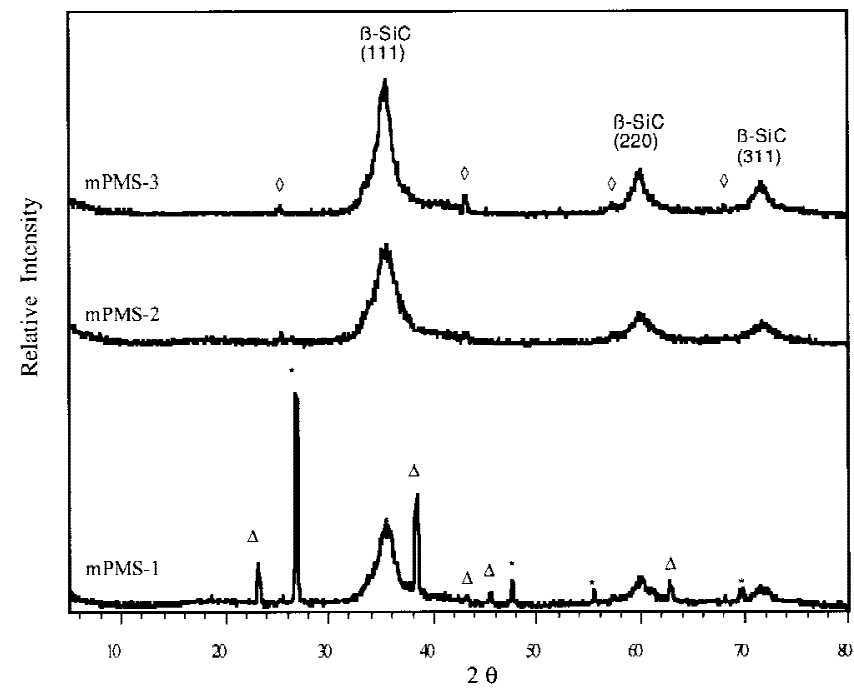

Fig. 5. XRD patterns of mPMS-1, -2 , and -3 pyrolyzed to $1400^{\circ} \mathrm{C}$ $((\diamond)$ graphitic carbon, $(\star)$ silicon, and $(\triangle)$ ByC). (See Table $V$ for powder diffraction file card numbers.)

ders, e.g., $\mathrm{SiO}_{2}$ on $\mathrm{SiC}$, providing access to well-controlled interfaces. Prochazka and Scanlan ${ }^{52}$ find that submicrometer $\mathrm{SiC}$ powders sinter effectively when both boron and carbon additives are used. In contrast, precursor-derived oxide-free $\mathrm{SiC}$ sinters when boron is added but not carbon, ${ }^{36}$ suggesting that excess carbon aids removal of surface oxide layers.

(D) DRIFTS: DRIFTS spectra of SiC (mPMS) formed at $\leq 1000^{\circ} \mathrm{C}$ suggest the presence of some oxygen, as indicated by a small $v_{\mathrm{Si}-\mathrm{O}}$ band $\left(1040 \mathrm{~cm}^{-1}\right)$. The oxygen content can be estimated from the $\nu_{\mathrm{Si}-\mathrm{C}}$ and $\nu_{\mathrm{Si}-\mathrm{O}}$ peak ratios. Tsuge et al. ${ }^{53}$ report that mixtures containing $\mathrm{SiC}$ and $\mathrm{SiO}_{2}$ exhibit a linear relationship between the $\mathrm{SiO}_{2}$ concentration and observed $v_{\mathrm{Si}-\mathrm{O}}$ intensity. On this basis, $1100^{\circ} \mathrm{C} \mathrm{SiC}$ (mPMS) has $<1 \mathrm{wt} \%$ oxygen.

Oxygen incorporation likely results from slow oxidation (by adventitious oxygen) of retained $\mathrm{Si}-\mathrm{H}$ bonds, to form $\mathrm{Si}-\mathrm{O}$ bonds. No $v_{\mathrm{Si}-\mathrm{O}}$ bands are present in samples heated to $1200^{\circ} \mathrm{C}$, indicating oxidation is avoided or $\mathrm{SiO}$ loss occurs. This suggests that precursor processing must be conducted with care before full mineralization at $\geq 1200^{\circ} \mathrm{C}$ to limit impurity incorporation.

DRIFTS spectra of $\mathrm{SiC}$ (mPMS) heated to $\geq 1200^{\circ} \mathrm{C}$ (Fig. 6) show broad peaks attributable to $\mathrm{SiC}(900$ and 780 $\left.\mathrm{cm}^{-1}\right){ }^{36,53,54}$ The $\delta_{\mathrm{Si}-\mathrm{CH}_{3}}\left(1400 \mathrm{~cm}^{-1}\right), \delta_{\mathrm{Si}-\mathrm{CH}_{2}-\mathrm{Si}}\left(1355 \mathrm{~cm}^{-1}\right)$, and $\nu_{\mathrm{Si}-\mathrm{H}}\left(2100 \mathrm{~cm}^{-1}\right)$ absorptions observed for $1000^{\circ} \mathrm{C}(2 \mathrm{~h})$ samples are absent in spectra of $1200^{\circ}$ and $1400^{\circ} \mathrm{C}$ samples, in accord with the mass loss attributed to hydrogen-gas evolution seen in the TGA. These changes indicate that the mPMS-to$\mathrm{SiC}$ transformation is incomplete until $\geq 1200^{\circ} \mathrm{C}$.

The breadth of the $\mathrm{Si}-\mathrm{C}$ peak $\left(\sim 850 \mathrm{~cm}^{-1}\right)$ observed in the $1000^{\circ} \mathrm{C}$ DRIFTS is a result of the highly disordered nanocrystalline material produced. ${ }^{25,36}$ As the pyrolysis temperature is increased from $1200^{\circ}$ to $1400^{\circ} \mathrm{C}$, the $850 \mathrm{~cm}^{-1}$ peak sharpens and becomes better resolved, indicating better ordering and crystallinity.

\section{(3) AlN-SiC Powder Characterization}

(A) XRD Analyses: The XRD patterns of as-received $\mathrm{AlN}$ and $\alpha$-SiC powders (average particle size of 0.3 and $10-20$ $\mu \mathrm{m}$, respectively, Fig. 1) are typical of highly crystalline hexagonal phases (see Table V for powder diffraction files). One difficulty with XRD analysis of the AlN-SiC system is that many peaks overlap. For example, (102), the most intense peak for $\alpha-\operatorname{SiC}\left(35.66^{\circ} 2 \theta\right)$ is obscured by the AlN (002) peak $\left(36.04^{\circ} 2 \theta\right)$. The difficulty increases when both $\alpha$ - and $\beta$-SiC are present with AlN, because all four peaks of the $\beta$ phase coincide with those of the $\alpha$-phase (Table IV). In principle, the microstructural evolution of SiC (mPMS) should be easy to follow given the broad XRD peaks typically generated from nanocrystalline $\beta$-SiC. However, this becomes impossible when seeding occurs.

(B) DRIFTS: The as-received AlN material exhibits a peak centered at $\sim 770 \mathrm{~cm}^{-1}$, with a smaller shoulder (possibly $\mathrm{Al}-\mathrm{O}-\mathrm{N}$ ) as reported in literature. ${ }^{55,56}$ This shoulder increases slightly after $1000^{\circ} \mathrm{C}$ for $1 \mathrm{~h}$ under argon treatment, perhaps from crystallization. The AIN DRIFT spectra also show lowintensity $\nu_{\mathrm{OH}}$ and $\nu_{\mathrm{NH}}$ peaks. The low intensities appear to be artifacts of the analytical method. DRIFTS (Fig. 7) of asreceived and heat-treated $\mathrm{AlN}$ with $\sim 1 \mathrm{wt} \%$ oxygen (manufacturer's analysis) and hydrolysis products, should exhibit moreintense $v_{\mathrm{OH}}\left(3300-3500 \mathrm{~cm}^{-1}\right)$ and $v_{\mathrm{NH}}$ (from $\mathrm{NH}_{4}^{+}(1350$ $\left.\mathrm{cm}^{-1}\right)$ ) absorption peaks than actually observed.

Spectra of the coarse $\alpha-\operatorname{SiC}$ powders are difficult to obtain,

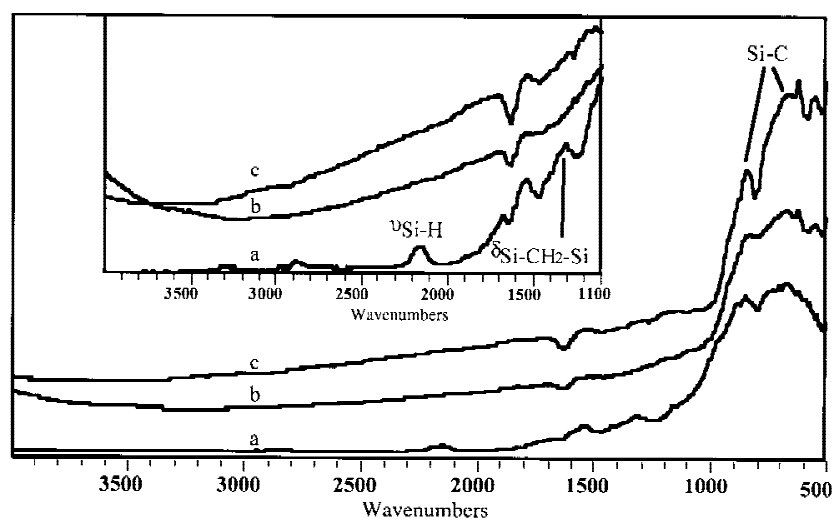

Fig. 6. Stacked DRIFTS spectra of mPMS-4 pyrolyzed to (a) $1000^{\circ}$, (b) $1200^{\circ}$, and (c) $1400^{\circ} \mathrm{C}$. Inset figure is magnified view of the 1100 $4000 \mathrm{~cm}^{-1}$ region. 
Table V. List of Powder Diffraction File Card Numbers and Representative Symbols Used in XRD Figures

\begin{tabular}{lllc}
\hline Phase & \multicolumn{1}{c}{ Structure } & \multicolumn{1}{c}{ File Card No. } & Figure symbol \\
\hline$\beta-\mathrm{SiC}$ & Cubic & $29-1129$ & Peaks labeled \\
$\alpha-\mathrm{SiC}$ & $6 H$ & $29-1128$ & Peaks labeled \\
AlN & Hexagonal & $25-1133$ & Peaks labeled \\
Silicon & Face-centered & $27-1402$ & $*$ \\
B $_{4} \mathrm{C}$ & Rhombohedral & $33-0225 / 35-0798$ & $\Delta$ \\
Carbon & Graphitic & $41-1487$ & $\diamond$ \\
\hline
\end{tabular}

"International Centre for Diffraction Data, Newtown Square, PA.

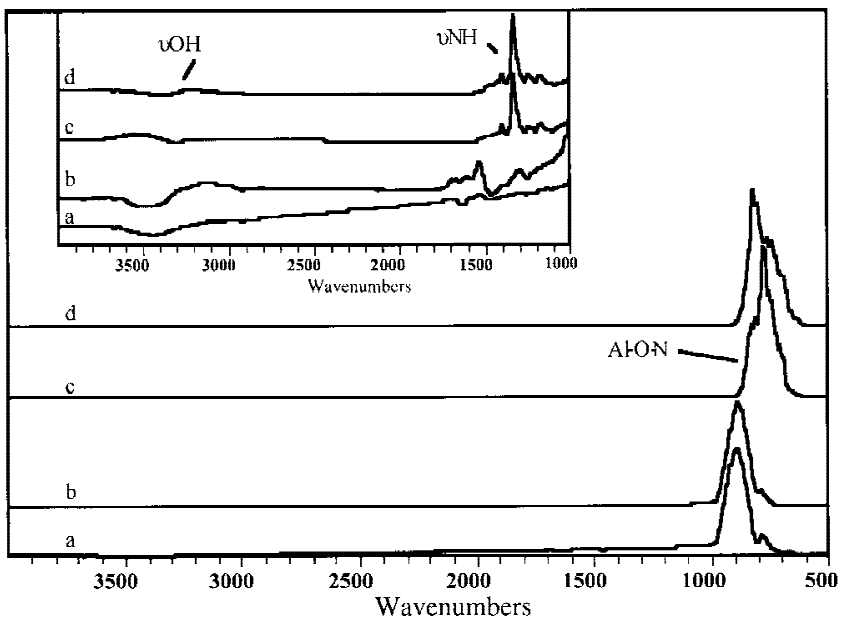

Fig. 7. DRIFTS of as-received (a) $\beta-\mathrm{SiC}$, (b) $\alpha-\mathrm{SiC}$, (c) AlN powders, and (d) AlN powder pyrolyzed at $1000^{\circ} \mathrm{C}$ for $1 \mathrm{~h}$ in argon. Inset figure is a magnified view of the $1000-4000 \mathrm{~cm}^{-1}$ region.

because the large particles cause significant specular reflectance and signal attenuation. Thus, submicrometer $\alpha$-SiC particles (CERAC, Inc., Milwaukee, WI) were substituted (identical XRDs). Two main absorption peaks for $\alpha$-SiC are present, with the primary peak centered at $900 \mathrm{~cm}^{-1}$ and a smaller peak at $780 \mathrm{~cm}^{-1}$. DRIFTS spectra for submicrometer $\alpha-$ and $\beta-S i C$ (CERAC) are indistinguishable. Both materials appear oxygenfree, because no $\nu_{\mathrm{Si}-\mathrm{O}}$ peaks are visible, despite the likely presence of surface $\mathrm{Si}-\mathrm{O}$.

\section{(4) Polymer Infiltration and Pyrolysis Processing}

The green compact density is controlled by the (1) ceramic particle-size distribution, (2) concentration of mPMS-4 binder used, and (3) compaction pressure. A $138 \mathrm{mPa}$ (20 ksi) uniaxial compaction pressure is most effective in producing strong and relatively dense compacts. Compacts pressed with AlN or AlN- $\alpha$-SiC powders exhibit green densities of $\sim 1.65 \mathrm{~g} / \mathrm{cm}^{3}$ ( $51 \%$ of theory, rule of mixtures).

The advantages of using mPMS-4 binder include (1) higher compact densities, (2) formation of more-uniform SiC (mPMS) coatings on the ceramic particles, (3) introduction of large charge of mPMS in the initial step, and (4) better potential for forming the continuous porous network required for PIP processing.

The green densities of disks with mPMS binder (20, 25, and $30 \mathrm{wt} \%)$ are slightly lower than the binder-free compacts at $1.60-1.65 \mathrm{~g} / \mathrm{cm}^{3}$. However, the $1000^{\circ} \mathrm{C}$ densities (zero PIP cycles) are significantly higher, $\geq 1.85 \mathrm{~g} / \mathrm{cm}^{3}$ or $60 \%$ of theory. This increase results primarily from partial sintering, because disks typically lose $\sim 20$ vol\%. Optimum densification is observed for 20-25 wt\% binder loadings, which agrees well with theory. ${ }^{53}$

To our knowledge, this apparent precursor-promoted sintering at $1000^{\circ} \mathrm{C}$ has not been reported before. There are several possible reasons sintering might occur, some based on reaction chemistry arguments and some based on physical rearrange- ment processes. Without further detailed study, any rationale would be too speculative at this point. However, understanding the processes involved may provide the means to fully consolidate PRCs at $\sim 1000^{\circ} \mathrm{C}$.

Once the binder/powder system was optimized for green density and processability, PIP processing studies began.

\section{(5) Infiltration Studies/Density Changes}

Preliminary studies were made at shorter times; however, 12 $\mathrm{h}$ immersion times were then used for all PIP studies. Bubble streams appeared immediately upon sample immersion and occasionally obscured the sample completely. The rate of bubble evolution decreased slowly for the first four PIP cycles, but decreased rapidly after four cycles.

The rate of density gain from mPMS-4 uptake with the number of PIP cycles was similar for all samples with or without mPMS-4 binder and/or $\alpha$-SiC particles. This result was significant, because the observed sintering in samples with mPMS-4 binder apparently did not hinder subsequent infiltration efforts. This implied that sintering was not accompanied by significant pore closure.

The gases evolved during mPMS conversion to $\mathrm{SiC}$ may have been important in maintaining a continuous pore structure. Because samples with mPMS-4 binder had higher green densities, fewer PIP cycles were required to achieve higher densities. Moreover, the maximum densities achieved were also higher with mPMS-4 binder. For example, the maximum densities obtained for mPMS binderless disks were $\sim 2.2 \mathrm{~g} / \mathrm{cm}^{3}$ after nine PIP cycles and $1400^{\circ} \mathrm{C}$ heat treatments (Fig. 8). In comparison, the highest densities obtained for samples with 20 wt\% mPMS binder after nine PIP cycles were $\sim 2.5 \mathrm{~g} / \mathrm{cm}^{3}$ (theoretical density is $\sim 3.1 \mathrm{~g} / \mathrm{cm}^{3}$ by rule of mixtures).

The above densities were obtained using a staged heating/ infiltration schedule. Disks were cycled at $1000^{\circ} \mathrm{C}$ for three or four cycles, followed by an intermediate cycle at $1200^{\circ} \mathrm{C}$. The advantages of repeated PIP cycling to $1000^{\circ} \mathrm{C}$ included shorter processing times and minimum use of high temperatures. Processing at $1200^{\circ}$ or $1400^{\circ} \mathrm{C}$ led to higher $\mathrm{SiC}$ (mPMS) densities $\left(\rho \approx 2.4 \mathrm{~g} / \mathrm{cm}^{3}\right)^{36}$ and was used to reopen capillary pores. This resulted in improved precursor infiltration during subsequent cycles.

Slower heating rates were used during the first heat treatment of the more-fragile green compacts to minimize gas evolution. Faster heating rates (to $1000^{\circ} \mathrm{C}$ ) were possible in subsequent cycles, because the compact's mechanical integrity increased considerably beyond the zeroth PIP cycle. Heat treatments to $1400^{\circ} \mathrm{C}$ were performed at up to $25^{\circ} \mathrm{C} / \mathrm{min}$. Samples were heat-treated at $1400^{\circ} \mathrm{C}$ for $1 \mathrm{~h}$ under argon when mPMS-4 uptake did not improve after a $1200^{\circ} \mathrm{C}$ heat treatment.

The $1400^{\circ} \mathrm{C}$ heat treatments gave no further sintering/

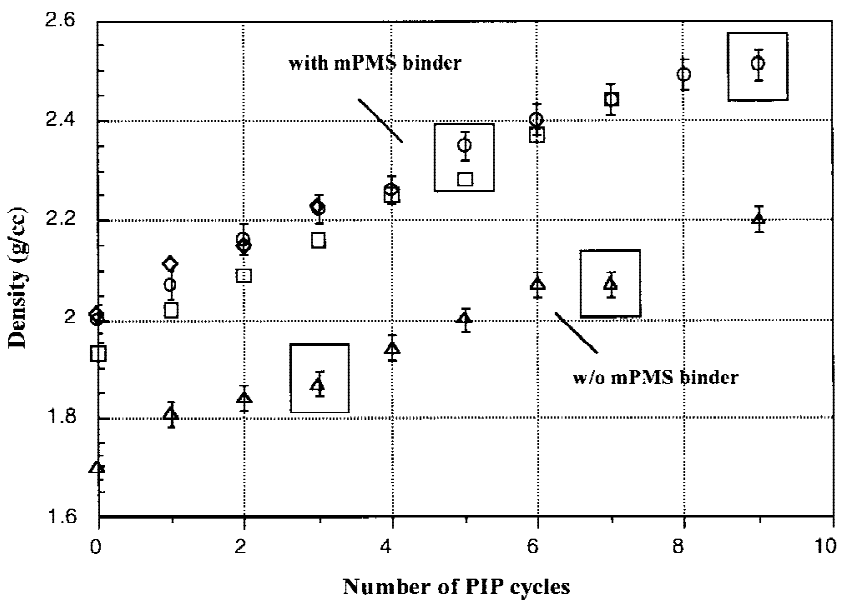

Fig. 8. Density increase for $\mathrm{AlN}-\mathrm{SiC}$ disks with and without mPMS binder. Boxed data points represent $1200^{\circ} \mathrm{C}$ PIP cycles. Final PIP cycle went to $1400^{\circ} \mathrm{C}$. 


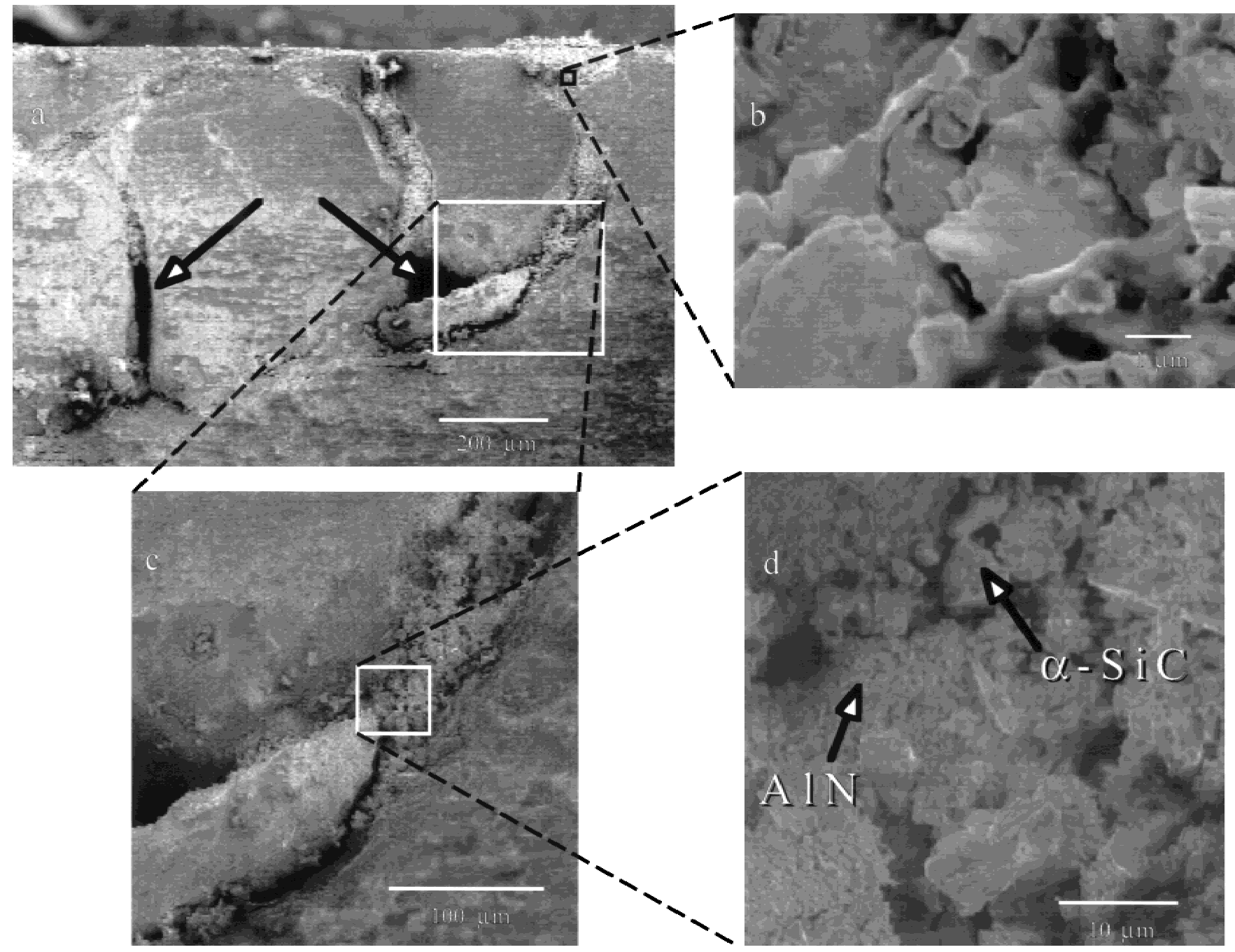

Fig. 9. SEMs of AlN- $\alpha-S i C$ disk after nine PIP cycles: (a) primary area of observation, (b) view of a pore channel filled with SiC (mPMS), (c) magnified view of a crack region, and (d) phases present near the crack.

densification, in contrast to the work of Zhang, ${ }^{36}$ who showed that $\mathrm{SiC}$ (mPMS) continued to densify at higher temperatures, approaching full density $\left(3.21 \mathrm{~g} / \mathrm{cm}^{3}\right)$ at $\sim 1800^{\circ} \mathrm{C}$. The absence of densification could be explained if the added $\alpha-\mathrm{SiC}$ seeded crystallization, because the $\mathrm{SiC}$ formed was fully dense, which appears to occur as discussed below.

The final densities of $\sim 2.5-2.6 \mathrm{~g} / \mathrm{cm}^{3}$ obtained at nine PIP cycles indicates the presence of residual, closed macroporosity of $\sim 20 \%$, assuming all of the mPMS-4 transforms to fully dense SiC. Therefore, additional modifications are required to achieve higher density samples within the preset 10 PIP cycles limit, perhaps by using higher polymer concentrations during impregnation, higher heat-treatment temperatures, or HPing. However, this degree of porosity is typical of PIP, CVI, and CVD methods of producing composites.

\section{(6) Microstructural Changes}

(A) SEM: SEM of AlN- $\alpha-S i C-m P M S$ disk cross sections (Fig. 9; $\rho \approx 2.5 \mathrm{~g} / \mathrm{cm}^{3}$ after nine PIP cycles at $1400^{\circ} \mathrm{C}$ maximum temperature) reveals few macroscopic voids. However, substantial micrometer-sized porosity is evident. Some clogged pores are visible (Fig. 9(a)) near the specimen surface (within $\sim 100 \mu \mathrm{m}$ ).

Three separate phases can be identified by their distinct morphologies. The submicrometer AlN particles are the most abundant and appear unchanged by the PIP process (Fig. 9(c) and (d)). The edges of several $\alpha$-SiC particles are visible. These large $\alpha$-SiC particles are almost completely surrounded by the much smaller AlN particles. Nanocrystalline SiC appears in the third phase, primarily in the filled pore channels (Fig. 9(b)).

The observed macroscopic voids (arrows in Fig. 9(a)) are likely cracks from compressive stresses caused by the drying polymer. Similar cracks are observed by Tu and Lange ${ }^{39,40}$ in polymer-infiltrated powder compacts. These authors find that removing the surface polymer layer before pyrolysis reduces the compressive stresses and prevents surface cracks from occurring. The cracks in AlN-SiC compacts are filled during subsequent PIP cycles. The presence of the cracks was discovered only on sectioning. Crack healing near the surface appears complete, because the original crack edges are barely observable. However, healing appears limited to cracks $\leq 400 \mu \mathrm{m}$ deep (Fig. 9(a)). The limit on infiltration depth may result because of surface pore collapse and residual gases trapped within the crack, which prevent complete pore filling. If true, improved densities may be accessible simply by pressure- or vacuum-assisted infiltration.

(B) XRD: Work on $\mathrm{SiC}-\mathrm{SiC}$ composites conducted in our laboratory and a related HRTEM study by Bill and coworkers $^{50}$ indicates that $\mathrm{SiC}$ powders seed $\mathrm{SiC}$ (mPMS) crystallization. The similarity in the basal plane lattice parameters $^{12,15-18,21,24}$ between $2 H$-AlN and $\alpha$-SiC suggests that AIN may seed $\mathrm{SiC}$ (mPMS) crystallization. This possibility has been tested by mixing submicrometer AlN powder and mPMS-4 in a 3:1 ratio (by weight) and heating the mixture to different temperatures. The resulting materials have been characterized by XRD, TGA, and DRIFTS. Three AIN-mPMS-4 experi- 


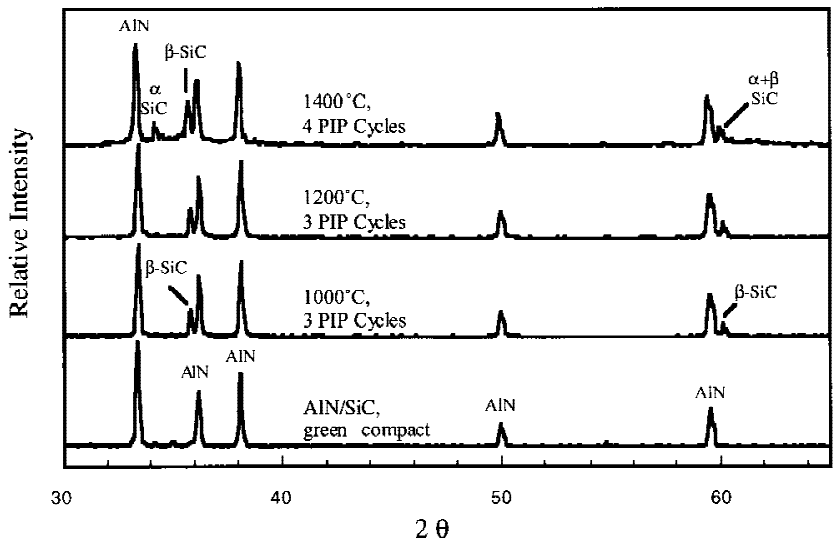

Fig. 10. Stacked XRDs of AlN- $\alpha-S i C$ disks showing evolution of $\mathrm{SiC}$ (mPMS) after different stages of PIP processing. Temperatures and the number of PIP cycles shown indicate the maximum heat treatment used and the cumulative total of cycles.

ments have been conducted to determine the effect of AlN concentrations on the crystallization behavior of $\mathrm{SiC}$ (mPMS).

XRD analyses of $3: 1$ (by weight) mixtures of AlN-SiC (mPMS) pyrolyzed to selected temperatures show only sharp AlN peaks, identical to those in Fig. 1, with no detectable $\beta$-SiC, even at $1400^{\circ} \mathrm{C}$. In contrast, small, discrete $\beta$-SiC peaks are detected when samples of AIN and SiC (mPMS) are heated individually to $1400^{\circ} \mathrm{C}$, ground, and then mixed in a 3:1 ratio. XRD analyses of 1:4 (by weight) AlN-mPMS-4 mixtures heated to $1200^{\circ}$ to $1400^{\circ} \mathrm{C}$ suggest that $\mathrm{SiC}$ (mPMS) does not nucleate on AlN particles. Broad peaks, typical of $\beta-S i C$ $(\mathrm{mPMS})$ are visible at $1200^{\circ} \mathrm{C}$ and remain broad even at $1400^{\circ} \mathrm{C}$. The graphitic carbon normally seen with $\mathrm{SiC}$ (mPMS) derived from mPMS-4 is missing, presumably because of reaction with surface oxygen on AlN particles.

The final system studied consists of $\alpha-\mathrm{SiC}$ seeds mixed with AlN-mPMS-4. XRDs of pyrolyzed AlN- $\alpha-S i C$ disks infiltrated with mPMS-4 (Fig. 10) suggest that seeded crystallization occurs. Figure 10(a) is from a green, as-pressed AlN- $\alpha$ SiC disk, with no mPMS-4 binder. The other XRD patterns are of a single disk with mPMS-4 binder at different processing stages.

No $\mathrm{SiC}$ peaks result from the as-pressed disk, despite the 10 wt $\% \alpha$-SiC. After three $1000^{\circ} \mathrm{C}$ PIP cycles, peaks at $35.60^{\circ}$ (assigned to $\beta-\mathrm{SiC}$ ) and $59.98^{\circ} 2 \theta$ appear. The (101) peak for $6 H-\alpha-\operatorname{SiC}\left(34.09^{\circ} 2 \theta, 35 \%\right.$ of most intense peak $^{\S}$ is used to distinguish between the $\alpha$ and $\beta$ phases. The enhanced intensity and narrow $\beta$-SiC peaks shown in Fig. 10 indicate much greater crystallinity than shown in Fig. 5. No changes are observed in the XRD pattern when the same disk is heated to $1200^{\circ} \mathrm{C}$, without additional PIP cycles (Fig. 10(c)). However, significant changes are detected after a fourth $1000^{\circ} \mathrm{C}$ PIP cycle followed immediately by heating to $1400^{\circ} \mathrm{C}$. The $(101)$ peak for $6 H-\alpha-S i C\left(34.09^{\circ} 2 \theta\right)$ is now present (Fig. 10(d)), while the $\mathrm{SiC}$ peak at $35.6^{\circ} 2 \theta$ increases slightly; the AlN peak at $36.04^{\circ} 2 \theta$ is used as a reference.

Several explanations can account for these observations. The first is that the $\beta-\mathrm{SiC}$ phase is present at $1000^{\circ}$ and $1200^{\circ} \mathrm{C}$, and partially transforms to $\alpha$ phase after heating to $1400^{\circ} \mathrm{C}$. The second possibility is that nanocrystalline $\alpha-\mathrm{SiC}$ is formed with $\beta-\mathrm{SiC}$, even at $1000^{\circ} \mathrm{C}$, and grain growth occurs when heated to $1400^{\circ} \mathrm{C}$, leading to the appearance of the peak at $34^{\circ} 2 \theta$. $\mathrm{SiC}$ (mPMS) typically contains minor amounts $(\sim 15 \mathrm{wt} \%)$ of $\alpha-\mathrm{SiC}^{36}$

The first explanation is considered more plausible. Because

\footnotetext{
${ }^{\S}$ Powder Diffraction File, Card No. 29-1128. International Centre for Diffraction Data, Newtown Square, PA.
}

AlN does not seed crystallization of $\mathrm{SiC}$ (mPMS), the $10 \mathrm{wt} \%$ $\alpha$-SiC CERAC powder used in the compact must be responsible for the enhanced crystallization observed. However, the absence of the $34^{\circ} 2 \theta$ peak at $1000^{\circ}$ and $1200^{\circ} \mathrm{C}$ suggests that $\alpha$-SiC promotes crystallization of $\beta$-SiC (in accord with Bill and co-workers ${ }^{50}$ ), and the $\beta$ - to $\alpha$-phase transformation occurs only at $1400^{\circ} \mathrm{C}$. The observed peaks are much sharper than normally expected for SiC (mPMS).

The (110) peak splitting observed at $59.40^{\circ}$ and $59.95^{\circ} 2 \theta$ (in Figs. 10(b-d)) is unusual and, based on the work of Miura et al.,${ }^{17}$ suggests that the formation of an $\mathrm{AlN}-\mathrm{SiC}$ solid solution has occurred. Normally, the AIN and SiC (110) peaks overlap (as in Fig. 10(a)); however, XRD results by Miura et al. ${ }^{17}$ indicate similar (110) peak separation at $59.46^{\circ}$ and $59.93^{\circ} 2 \theta$. These authors claim that the peak shifts result because AlN-SiC composites with modulated nanoscale AlNrich-SiC-rich texture are produced by spinodal decomposition of AlN-SiC solid solutions. Thus, one interpretation of the peak splitting we observe is that an $\mathrm{AlN}-\mathrm{SiC}$ solid solution forms that subsequently produces an $\mathrm{AlN}-\mathrm{SiC}$ nanocomposite. Further work is required to validate this possibility.

(C) TGA: The predicted and actual weight losses for these mixtures are consistent (within 1\%) with that expected from the behavior of the individual components on heating to $1000^{\circ} \mathrm{C}$. For example, the actual AlN-SiC (mPMS) weight $\left(1000^{\circ} \mathrm{C}\right.$, TGA) is $0.350 \mathrm{~g}$, whereas the weight predicted assuming an $85 \mathrm{wt} \% \mathrm{CY}$ for mPMS-4 $\left(1000^{\circ} \mathrm{C}\right)$ is $0.351 \mathrm{~g}$. This suggests that the entire processing system is well behaved. No further weight loss is detected above $1000^{\circ} \mathrm{C}$, in keeping with the seeded crystallization. This also suggests that hydrogen loss is accelerated by seeding.

(D) DRIFTS: DRIFTS has been used to complement the XRD data. Because many different peaks (Al-N, Al-O, $\mathrm{Si}-\mathrm{C}, \mathrm{Al}-\mathrm{O})$ overlap, care must be taken in making peak assignments. The first step is to establish baseline spectra for the individual materials. Peaks obtained are also compared with literature values. ${ }^{53,55}$

DRIFTS can be highly sensitive to sample crystallinity, particle size, and bond type but is not as structure sensitive as XRD, because it probes at the atomic scale. For instance, minute amounts of $\mathrm{SiO}_{2}$, not detected by XRD, are detectable by infrared methods. In contrast, $\alpha$ - and $\beta-\mathrm{SiC}$, easily distinguishable by XRD, are indistinguishable by infrared methods.

Application of DRIFTS to the disks requires a modified, nondestructive, nonstandard approach. The sample thickness and opacity rule out use of transmission infrared methods. Instead, a method based on Koenig and co-workers ${ }^{57-61}$ is used, wherein thin layers of ground $\mathrm{KBr}$ powder are used to differentiate between glass substrates and polymeric surface coatings. The amount of powder (or $\mathrm{KBr}$ layer thickness) used controls the probing depth. ${ }^{59,60}$

To maintain sample consistency, a fixed amount of ground $\mathrm{KBr}$ powder is pressed into a die to give $\mathrm{KBr}$ pellets with a consistent thickness and good surface uniformity. These pellets can be used repeatedly, further reducing the error within a group of samples tested. The sample surfaces are not polished, because flat surfaces give specular rather than diffuse reflectance and lead to a lower signal-to-noise ratio. Moreover, the sampling depth for DRIFTS can be quite shallow (several micrometers) and is affected by sample reflectivity. ${ }^{57-61}$

Figure 11(a) is a DRIFTS spectrum for a green $\mathrm{AlN}-\alpha-\mathrm{SiC}$ disk with no $\mathrm{SiC}$ (mPMS). Two main absorption bands at 800 $900 \mathrm{~cm}^{-1}(\nu \mathrm{Si}-\mathrm{C})$ and centered at $700 \mathrm{~cm}^{-1}(\nu \mathrm{Al}-\mathrm{N})$ are observed. Figure 11(b) is the spectrum of a sample heat-treated to $1000^{\circ} \mathrm{C}$. The broad band (mixture of $\nu \mathrm{Si}-\mathrm{O}$ and $\nu \mathrm{Al}-\mathrm{O}$ ) at $1040 \mathrm{~cm}^{-1}$ results as $\mathrm{Si}-\mathrm{H}$ groups react with the $1 \mathrm{wt} \%$ oxygen initially present in the AlN. The AlN bands are likely masked by the larger $\nu \mathrm{Si}-\mathrm{O}$ band. This spectrum suggests considerable oxidation at the surface as the $\mathrm{Al}-\mathrm{N}$ and $\mathrm{Si}-\mathrm{C}$ bands are much diminished.

Figure 11(c) is similar to Fig. 11(a), except that a new peak 


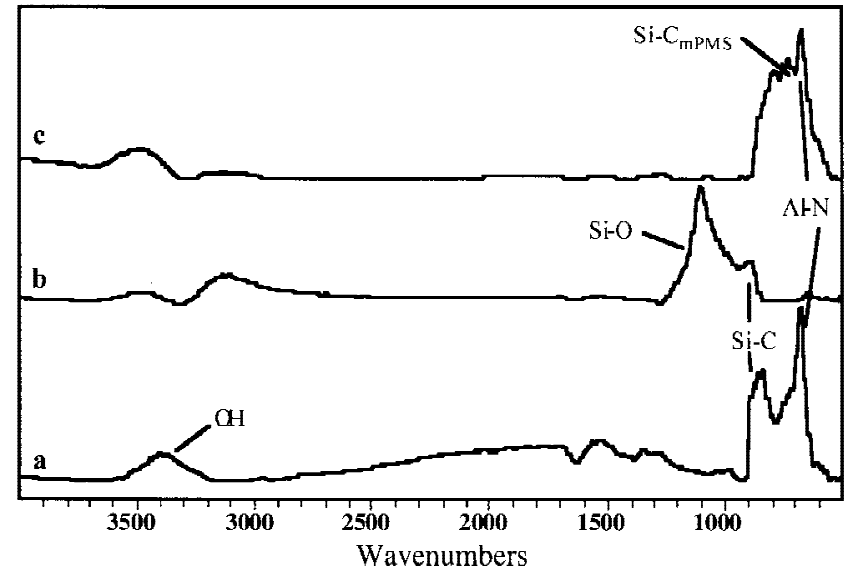

Fig. 11. DRIFTS of AIN- $\alpha-\mathrm{SiC}$ disks: (a) as-pressed, (b) with $\mathrm{SiC}(\mathrm{mPMS})$ after one $1000^{\circ} \mathrm{C}$ PIP cycle, and (c) with $\mathrm{SiC}$ (mPMS) after one $1400^{\circ} \mathrm{C}$ PIP cycle.

(from $\mathrm{SiC}(\mathrm{mPMS})$ ) is present and centered likely because the excess carbon from $\mathrm{SiC}$ (mPMS) carbothermally reduces the surface oxides in Fig. 11(b). These observations coupled with the TGA and FTIR data above suggest that SiC (mPMS) should be processed at $\geq 1200^{\circ} \mathrm{C}$ to allow complete carbothermal reduction of $\mathrm{SiC}_{2}$ and hydrogen evolution.

\section{Conclusions}

The feasibility of forming nanocrystalline AlN-SiC composites and solid solutions via a low-temperature PIP process with mPMS was studied. The use of organometallic polymer precursors allowed processing of nanocrystalline CMCs at relatively low temperatures $\left(<1600^{\circ} \mathrm{C}\right)$. A carbon-rich mPMS (mPMS-4) was used as a reinforcing phase and nonfugitive binder in $\mathrm{AlN}-\alpha-\mathrm{SiC}$ compacts. The excess carbon was added to provide phase-pure $\mathrm{SiC}$ (mPMS) by eliminating silicon formation and to aid removal of oxide layers on the particulate phases. Higher densities $\left(\sim 2.5 \mathrm{~g} / \mathrm{cm}^{3}\right.$ or $78 \%$ of theory) were obtained in samples with mPMS-4 binder, compared to samples without binder $\left(\sim 2.2 \mathrm{~g} / \mathrm{cm}^{3}\right)$. The mPMS binder caused the powder compacts to partially sinter at $1000^{\circ} \mathrm{C}$, without appreciable pore collapse, because density gains from subsequent PIP processing were unaffected.

The effects of adding $10 \mathrm{wt} \%$ (-325 mesh) of $\alpha$-SiC particles to AlN-PMS-4 powder compacts were considerable. XRD studies indicated that the $\alpha$-SiC seeded crystallization of $\mathrm{SiC}(\mathrm{mPMS})$. In contrast, AlN particles were found to have no effect on $\mathrm{SiC}(\mathrm{mPMS})$. Higher green compact strengths and crack healing also were attained with $\alpha-S i C$ addition. However, surface cracks in samples with $\alpha$-SiC healed during PIP processing. In contrast, the surface cracks grew, rather than healed, in samples of AlN with mPMS-4.

XRD and density gain results showed that composites of AlN-SiC with 20-30 wt\% SiC (mPMS) were formed, rather than complete solid solutions at the temperatures used, i.e., $\leq 1400^{\circ} \mathrm{C}$. However, there was one piece of evidence suggesting that partial solid-solution formation may have occurred, namely, the peak separation observed in at $60^{\circ} 2 \theta$. XRD data further suggested that $\beta$-phase $\mathrm{SiC}$ (mPMS) formed at $1000^{\circ}$ and $1200^{\circ} \mathrm{C}$ but partially transformed to $\alpha$-phase at $1400^{\circ} \mathrm{C}$.

Acknowledgments: The authors would like to thank Dr. Martha Fletcher of ARL for her continuing, generous, unflagging support and faith in our research program. We would like to thank Dr. R. Katz for interesting us in this area.

\section{References}

${ }^{1}$ J. A. Cornie, Y.-M. Chiang, D. R. Uhlmann, A. Mortensen, and J. M. Collins, "Processing of Metal and Ceramic Matrix Composites," Am. Ceram. Soc. Bull., 65 [2] 293-304 (1986).
${ }^{2}$ E. Fitzer and R. Gadow, "Fiber-Reinforced Silicon Carbide," Am. Ceram. Soc. Bull., 65 [2] 326-35 (1986).

${ }^{3}$ P. J. Lamicq, G. A. Bernhart, M. M. Dauchier, and J. G. Mace, "SiC/SiC Composite Ceramics," Am. Ceram. Soc. Bull., 65 [2] 336-38 (1986).

${ }^{4}$ M. A. Janney, "Microstructural Development and Mechanical Properties of SiC and of SiC-TiC Composites," Am. Ceram. Soc. Bull., 65 [2] 357-62 (1986).

${ }^{5}$ D. P. Stinton, A. J. Caputo, and R. A. Lowden, "Synthesis of FiberReinforced SiC Composites by Chemical Vapor Infiltration," Am. Ceram. Soc. Bull., 65 [2] 347-50 (1986).

${ }^{6}$ L. J. Schioler and J. J. Stiglich Jr., "Ceramic-Matrix Composites: A Literature Review," Am. Ceram. Soc. Bull., 65 [2] 289-93 (1986).

${ }^{7}$ X. Pan, J. Mayer, M. Rühle, and K. Niihara, "Silicon Nitride Based Ceramic Nanocomposites," J. Am. Ceram. Soc., 79 [3] 585-90 (1996).

${ }^{8} \mathrm{M}$. Landon and F. Thevenot, "The SiC-AlN System: Influence of Elaboration Routes on the Solid Solution Formation and Its Mechanical Properties," Ceram. Int., 17 [1] 97-110 (1991).

${ }^{9}$ C. K. Unni and D. E. Gordon, "Mechanical Properties of Monolithic AlN and $\mathrm{SiC}_{w}$ /AlN Composites," J. Mater. Sci., 30 [5] 1173-79 (1995).

${ }^{10} \mathrm{~J}$. Zhao, L. C. Stearns, M. P. Harmer, H. M. Chan, G. A. Miller, and R. F. Cook, "Mechanical Behavior of Alumina-Silicon Carbide 'Nanocomposites'," J. Am. Ceram. Soc., 76 [2] 503-10 (1993).

${ }^{11}$ A. M. Thompson, H. M. Chan, M. P. Harmer, and R. F. Cook, "Crack Healing and Stress Relaxation in $\mathrm{Al}_{2} \mathrm{O}_{3}-\mathrm{SiC}$ 'Nanocomposites'," J. Am. Ceram. Soc., 78 [3] 567-71 (1995)

${ }^{12}$ J.-L. Huang and J.-M. Jih, "Investigation of SiC-A1N System: Part I Microstructure and Solid Solution," J. Mater. Res., 10 [3] 651-58 (1995).

${ }^{13}$ J.-L. Huang and J.-M. Jih. "Investigation of SiC-AlN System: Part II. Mechanical Properties," J. Am. Ceram. Soc., 79 [5] 1262-64 (1996).

${ }^{14}$ R. N. Katz, S. Grendahl, K. Cho, I. Bar-On, and W. Rafaniello, "Fracture Toughness of Ceramics in the AlN-SiC System," Ceram. Eng. Sci. Proc., 15 [5] 877-84 (1994)

${ }^{15}$ R. Ruh, A. Zangvil, and J. Barlowe, "Elastic Properties of SiC, AlN, and Their Solid Solutions and Particulate Composites," Am. Ceram. Soc. Bull., 64 [10] 1368-73 (1985)

${ }^{16} \mathrm{~W}$. Rafaniello, M. R. Plichta, and A. V. Virkar, "Investigation of Phase Stability in the System SiC-AlN," J. Am. Ceram. Soc., 66 [4] 272-76 (1983).

${ }^{17}$ M. Miura, T. Yogo, and S.-I. Hirano, "Phase Separation and Toughening of SiC-AlN Solid-Solution Ceramics," J. Mater. Sci., 28 [7] 3859-65 (1993).

${ }^{18}$ R.-R. Lee and W.-C. Wei, "Fabrication, Microstructure, and Properties of SiC-AlN Ceramic Alloys," Ceram. Eng. Sci. Proc., 11 [7-8] 1094-21 (1990).

${ }^{19}$ W.-C. Wei and R.-R. Lee, "Pressureless Sintering of AlN-SiC Composites," J. Mater. Sci., 26 [6] 2930-36 (1991).

${ }^{20} \mathrm{Y}$. Xu and A. Zangvil, "Formation of $\beta$-SiAlON as an Intermediate Oxidation Product of SiC-AlN Ceramics," J. Am. Ceram. Soc., 78 [10] 2753-62 (1995)

${ }^{21}$ (a) A. Zangvil and R. Ruh, "Phase Relationships in the Silicon CarbideAluminum Nitride System," J. Am. Ceram. Soc., 71 [10] 884-90 (1988). (b) R. Ruh and A. Zangvil, "Composition and Properties of Hot-Pressed SiC-AlN Solid Solutioins," J. Am. Ceram. Soc., 65 [5] 260-65 (1982).

${ }^{22}$ M. F. Denanot and J. Rabier, "Characterization of the Microstructure of Sintered AlN by Transmission Electron Microscopy," Mater. Sci. Eng. A, 109 [3] 157-60 (1989).

${ }^{23}$ T. Ohji, T. Hirano, A. Nakahira, and K. Niihara, "Particle/Matrix Interface and Its Role in Creep Inhibition in Alumina/Silicon Carbide Nanocomposites," J. Am. Ceram. Soc., 79 [1] 33-45 (1996).

${ }^{24}$ R. Sathyamoorthy, A. V. Virkar, and R. A. Cutler, "Damage-Resistant SiC-AlN Layered Composites with Surface Compressive Stresses," J. Am. Ceram. Soc., 75 [5] 1136-41 (1992).

${ }^{25} \mathrm{H}$. Gleiter, "Materials with Ultrafine Microstructures: Retrospectives and Perspectives," Nanostruct. Mater., 1, 1-19 (1992).

${ }^{26}$ A. Ezis and J. A. Rubin, "Nontraditional Densification Process, Hot Pressing"; pp. 186-92 in Engineered Materials Handbook, Glasses and Ceramics, Vol. 4. ASM International, Materials Park, OH, 1991.

${ }^{27}$ S.-Y. Kuo and A. V. Virkar, "Morphology of Phase Separation in AlN$\mathrm{Al}_{2} \mathrm{OC}$ and SiC-AlN Ceramics," J. Am. Ceram. Soc., 73 [9] 2640-46 (1990).

${ }^{28} \mathrm{M}$. Hirano, K. Kato, T. Isobe, and T. Hirano, "Sintering and Characterization of Fully Dense Aluminum Nitride Ceramics," J. Mater. Sci., 28 [9] 472530 (1993).

${ }^{29}$ S. R. Witek, G. A. Miller, and M. P. Harmer, "Effects of $\mathrm{CaO}$ on the Strength and Toughness of AlN," J. Am. Ceram. Soc., 72 [3] C-469-C-473 (1989).

${ }^{30} \mathrm{O}$. Shaling, M. Kulig, and P. Greil, "Preparation of Ca-2,2,2-Trifluoroethanolate as a Sintering Additive for AlN Ceramics," J. Mater. Sci. Lett., 13 [13] 977-79 (1994).

${ }^{31}$ C. L. Czekaj, M. L. J. Hackney, W. J. Hurley Jr., L. V. Interrante, G. A. Sigel, P. J. Shields, and G. A. Slack, "Preparation of Silicon Carbide/Aluminum Nitride Ceramics Using Organometallic Precursors," J. Am. Ceram. Soc., 73 [2] 352-57 (1990)

${ }^{32}$ R. T. Paine, J. F. Janik, and C. K. Narula, "Synthesis of AlN and AlN/SiC Ceramics from Polymeric Molecular Precursors," Mater. Res. Soc. Symp. Proc., 121, 461-64 (1988).

${ }^{33}$ R. M. Laine and F. Babonneau, "Preceramic Routes to Silicon Carbide," Chem. Mater., 5 [3] 260-79 (1993)

${ }^{34}$ L. V. Interrante, G. A. Sigel, M. Garbauskas, C. Hejna, and G. A. Slack, "Organometallic Precursors to AlN: Synthesis and Crystal Structures of $\left[\left(\mathrm{CH}_{3}\right)_{2} \mathrm{AlNH}_{2}\right]_{3}$ and the Planar Species $\left[\left(t-\mathrm{C}_{4} \mathrm{H}_{9}\right)_{2} \mathrm{AlNH}_{2}\right]_{3}$, " Inorg. Chem., 29 [1] 252-57 (1989).

${ }^{35}$ T. Wade, J. Park, E. G. Garza, C. B. Ross, D. M. Smith, and R. M. Crooks, "Electrochemical Synthesis of Ceramic Materials. 2. Synthesis of AlN and an 
AlN Polymer Precursor: Chemistry and Materials Characterization," J. Am. Chem. Soc., 114 [11] 9457-64 (1992).

${ }^{36}$ Z.-F. Zhang, C. S. Scotto, and R. M. Laine, "Processing Stoichiometric Silicon Carbide Fibers from Polymethysilane. I. Precursor Fiber Processing," $J$. Mater. Chem., 8, 2715-24 (1999).

${ }^{37}$ B. R. Maple and D. J. Green, "Incorporation of Mullite as a Second Phase into Alumina by an Infiltration Technique," J. Am. Ceram. Soc., 71 [11] C-471C-473 (1988).

${ }^{38}$ K. S. Mazdiyasni, R. West, and L. D. David, "Characterization of Organosilicon Infiltrated Porous Reaction-Sintered $\mathrm{Si}_{3} \mathrm{~N}_{4}$, , J. Am. Ceram. Soc., 61 [11-12] 504-508 (1978).

${ }^{39}$ W.-C. Tu and F. F. Lange, "Liquid Precursor Infiltration Processing of Powder Compacts: I, Kinetic Studies and Microstructures Development," J. Am. Ceram. Soc., 78 [12] 3277-82 (1995).

${ }^{40} \mathrm{~W}$.-C. Tu and F. F. Lange, "Liquid Precursor Infiltration Processing of Powder Compacts: II, Fracture Toughness and Strength," J. Am. Ceram. Soc., 78 [12] 3283-89 (1995).

${ }^{41}$ T. Hinklin, S. S. Neo, K. W. Chew, and R. M. Laine, "Precursor Impregnation and Pyrolysis (PIP) Processing of Barium Aluminosilicate-Nicalon Composite," manuscript in preparation.

${ }^{42}$ K. K. Chawla, Composite Materials Science and Engineering; pp. 134-36. Springer-Verlag, Berlin, Germany, 1987.

${ }^{43}$ K. B. Schwartz and D. J. Rowcliffe, "Modeling Density Contributions in Preceramic Polymer/Ceramic Powder Systems," J. Am. Ceram. Soc., 69 [5] C-106-C-108 (1986)

${ }^{44}$ P. Greil, "Active-Filler-Controlled Pyrolysis of Preceramic Polymers," J. Am. Ceram. Soc., 78 [4] 835-48 (1995).

${ }^{45}$ K. Waldner, R. M. Laine, C. R. Bickmore, S. Dhumrongvaraporn, and S. Tayaniphan, "Synthesis, Processing, and Pyrolytic Transformation of a Spine Polymer Precursor Made from $\mathrm{MgO}$ and $\mathrm{Al}(\mathrm{OH})_{3}$," Chem. Mater., 8, 2850-57 (1996)

${ }^{46}$ (a) R. M. Laine, B. L. Mueller, and T. Hinklin, "Neutral and Mixed Neutral/Anionic Polymetallooxanes," U.S. Pat. No. 5418 298, May 23, 1995. (b) R. M. Laine, D. R. Treadwell, B. L. Mueller, C. R. Bickmore, K. F. Waldner, and T. Hinklin, "Processable Aluminosilicate Alkoxide Precursors from Metal Oxides and Hydroxides. The Oxide One Pot Synthesis (OOPS) Process," J. Chem. Mater., 6, 1441-43 (1996).

${ }^{47}$ D.-L. Yang, D.-S. Tsai, and H.-C. Liu, "Raising Pyrolysis Yield of Preceramic Polymers of Silicon Carbonitride," J. Mater. Sci., 30 [9] 4463-68 (1995)

${ }^{48}$ A. Sellinger, "Synthesis and Characterization of Organosilicon-Based Poly- mers for Use as Precursors to Organic-Inorganic Hybrids and SiC"; Ph.D. Thesis. University of Michigan, Ann Arbor, MI, 1997.

${ }^{49}$ M. Nechanicky, K. W. Chew, and R. M. Laine, " $\alpha$-Silicon Carbide/ $\beta$ Silicon Carbide Particulate Composites via Polymer Infiltration and Pyrolysis Using Polymethylsilane, a Precursor to Stoichiometric $\beta$-Silicon Carbide," submitted for publication.

${ }^{50}$ (a) D. Heimann, T. Wagner, J. Bill, F. Aldinger, and F. F. Lange, "Epitaxial Growth of $\beta$-SiC Thin Films on a $6 \mathrm{H}$-SiC Substrate Using the Solution Precursor Method," J. Mater. Res., 12, 3099-101 (1997). (b) J. Bill, presented at the 20th Annual Cocoa Beach Conference on Composites, Advanced Ceramics, Materials, and Structures, Cocoa Beach, FL, Jan. 7-11, 1996.

${ }^{51}$ R. S. Hay, Wright Patterson Air Force Base, Dayton, OH; private communication.

${ }^{52}$ S. Prochazka and R. M. Scanlan, 'Effect of Boron and Carbon on Sintering of SiC," J. Am. Ceram. Soc., 58 [1-2] 72 (1975).

${ }^{53}$ A. Tsuge, Y. Uwamino, and T. Ishizuka, "Determination of Silicon Dioxide in Silicon Carbide by Diffuse Reflectance Infrared Fourier Transform Spectrometry," Appl. Spectrosc., 40 [3] 310-13 (1986).

${ }^{54}$ M.-T. S. Hsu, T. S. Chen, and S. R. Riccitiello, "Preceramic OrganoboronSilicon Polymers," J. Appl. Polym. Sci., 42, 851-61 (1991).

${ }^{55}$ J. G. Highfield and P. Bowen, "Diffuse-Reflectance Fourier Transform Infrared Spectroscopy Studies of the Stability of Aluminum Nitride Powder in an Aqueous Environment," Anal. Chem., 61 [11] 2399-402 (1989).

${ }^{56}$ R. A. Nyquist, Infrared Spectra of Inorganic Compounds $\left(3800-45 \mathrm{~cm}^{-1}\right)$; pp. 114-15. Academic Press, New York, 1971.

${ }^{57}$ M. T. McKenzie and J. L. Koenig, "Further Developments in the Methodology of Surface Analysis by FT-IR: Quantitative Aspects of Diffuse Reflectance Methods," Appl. Spectrosc., 39 [3] 408-12 (1985).

${ }^{58}$ S. R. Culler, M. T. McKenzie, L. J. Fina, H. Ishida, and J. L. Koenig, "Fourier Transform Diffuse Reflectance Infrared Study of Polymer Films and Coatings: A Method for Studying Polymer Surfaces," Appl. Spectrosc., 38 [6] 791-95 (1984)

${ }^{59}$ M. T. McKenzie, S. R. Culler, and J. L. Koenig, "Applications of Diffuse Reflectance FT-IR to the Characterization of an E-Glass Fiber $\gamma$-APS Coupling Agent System," Appl. Spectrosc., 38 [6] 786-90 (1984).

${ }^{60}$ J. L. Koenig, "Diffuse Reflectance FTIR Spectroscopy"; p. 49 in Spectroscopy of Polymers. ACS Professional Reference Book, Washington, DC, 1991.

${ }^{61}$ M. T. McKenzie, S. R. Culler, and J. L. Koenig; in Fourier Transform Infrared Characterization of Polymers. Edited by H. Ishida. Plenum, New York, 1987. 